\title{
Ongoing issues with the diagnosis of excited delirium
}

\author{
Roger W. Byard ${ }^{1}$
}

Accepted: 4 July 2017 /Published online: 3 August 2017

(C) Springer Science+Business Media, LLC 2017

Excited delirium refers to a clinical situation that is characterized by a series of typical features that include agitation, aggression and paranoia, intolerance to pain, unexpected physical strength, failure to tire despite constant physical activity, lack of clothing, rapid breathing, profuse sweating, elevated temperature, an attraction to glass or mirrors, and failure to respond to police or medical directives [1,2]. It has had a controversial history with suggestions being made that it is simply a "diagnosis" that has been used as a convenient way of covering up the use of excessive force by police officers [3].

One of the first descriptions of excited delirium was made in 1849 by Dr. Luther Bell, a psychiatrist who was working at the McLean Asylum for the Insane in Massachusetts, United States. So-called "Bell's mania manifested as acute exhaustive mania and delirium that was associated with a $75 \%$ fatality rate $[2,4]$. The numbers of cases fell after the introduction of major neuroleptic drugs in the 1950's but began to rise again in the 1980's with the increasing use of cocaine. Other drugs associated with excited delirium include methamphetamine, lysergic acid diethylamide (LSD) and phencyclidine (PCP). New designer drugs, such as the synthetic cathinones and NBOMe compounds, are also constantly appearing that may result in acute delirium $[5,6]$.

Delirium has been clearly defined in the medical literature as a transient state where there is disorganization of thought processes resulting in changes in cognition and consciousness with disorientation and difficulties separating reality from hallucinations [1]. The "excited" component is added when the

Roger W. Byard

roger.byard@sa.gov.au

1 School of Medical Sciences, The University of Adelaide, Frome Rd, Adelaide, SA 5000, Australia individual exhibits the features listed above. The term was coined in 1985 by Wetli and Fishbain [7], although it has been applied differently in different areas of medicine since then [8]. The victim is usually an obese male, aged in his thirties, with a history of either acute-on-chronic drug use or psychiatric illness such as schizophrenia or mania [5, 9-11].

A variety of asphyxial issues may arise during forcible restraint that range from direct crush asphyxia due to chest and abdominal compression caused by officers/individuals lying on top of a struggling individual, to direct neck compression from bar arm or carotid sleeper holds across the neck. Careful documentation of the presence or absence of facial and/or conjunctival petechiae, with layer dissection of the neck to check for, or to exclude, bruising, are all important components of the autopsy examination in such cases $[12,13]$. Abnormal positions of the body, particularly if hogtied face down with wrists and ankles bound together behind the back (the so-called prone maximal restraint position PMRP), may result in lethal positional asphyxia, although it has been questioned whether this position per se is sufficient to cause lethal asphyxia without other additive factors $[11,14]$.

In cases where there has not been asphyxia the lethal mechanisms may relate to hyperthermia, drug effect, or catecholaminergic cardio-respiratory failure from a "sympathetic storm" with lethal autonomic dysfunction $[2,11,15]$. Lethal ventricular arrhythmias are not common, with bradycardic and pulseless electrical activity being more usual, perhaps exacerbated by acidosis. The possibility of prolonged QT and Brugada syndromes should also be considered [5]. Rarely alternative mechanisms of death such as blunt craniofacial trauma may be reported [6]. Although the use of Tasers has been implicated in episodes of fatal excited delirium no definite causal relationship has been proven $[11,16]$. 
The levels of drugs detected in decedents have been similar to those found in recreational drug users, i.e. at levels lower than those where death has been attributed directly to the drug itself. Thus, simple drug overdose does not appear to be an issue [11]. Concomitant alcohol use has also been documented, but this is not always the case. The mortality rate has been difficult to determine given the lack of pathognomonic features, however it has been suggested that death only occurs in a small percentage of cases (most likely $<10 \%)$ [5].

A problem with excited delirium is that there is considerable overlap with the features of other conditions [5]. For example, the differential diagnosis includes substance abuse or withdrawal, hypoglycemia, neuroleptic malignant syndrome, heat stroke, serotonin syndrome, head injury, thyrotoxicosis, seizures, sepsis, electrolyte abnormalities, and hypoxia $[1,17]$. This means that there is an array of quite diverse conditions to check for at the time of autopsy. Muscle pallor may be a useful early macroscopic marker to identify rhabdomyolysis associated with hyperthermia and cocaine use [10].

Specialist, non-routine, neuropathological studies in decedents who have succumbed to excited delirium have shown alterations in dopamine processing most likely as a result of unopposed adrenergic stimulation. Dopamine transporters are reduced and there has been significant elevation in heat shock protein 70 . The exact triggers for these changes remain unclear, although it may affect primarily hypothalamic centers [1].

A number of controversies have raged around whether "excited delirium" can be considered a legitimate medical entity or not. For example, it has been pointed out that it is not a diagnosis listed in either the Diagnostic and Statistical Manual of Mental Disorders (DSM-IVTR) of the American Psychiatric Association, or in the International Classification of Diseases (ICD-10) of the World Health Organization [11]. However, although it is not listed in the ICD9/10, there are a number of codes that may cover excited delirium including: delirium (induced by drug or not), agitation (psychomotor), and abnormal/psychomotor/manic excitement (i.e. codes 292.81Q\&R; 293.1 J; 296.00S; 307.9 AD; 780.09E; and 799.2 AM,V\&X) [1].

While it has not been ratified as a diagnosis by medial organizations such as the American Medical Association or the American Psychiatric Association (APA), the National Association of Medical Examiners (NAME) and the American College of Emergency Physicians (ACEP) both recognize excited delirium as constituting a medical condition associated with an increased risk of sudden death $[1,18]$. In fact, the consensus of the American College of Emergency Physicians Task Force in 2012 was that "Excited Delirium Syndrome is a real syndrome, with uncertain, likely multiple, etiologies." [5].

Despite these endorsements it has not always been recognized in the courts. For example, in a finding handed down in the Australian state of Victoria in 2015, where the pathologist had attributed death to excited delirium, the coroner concluded that 'I find that 'Excited Delirium' and 'Excited Delirium Syndrome' are neither appropriate nor helpful for the ascribing of a medical cause of death" [19].

So, can excited delirium legitimately be used as a diagnosis? Certainly it would appear reasonable to use this term in non-lethal clinical cases and in fatalities with clearly documented collapse occurring during a typical episode, where there has been no unusual positioning of the body, or excessive use of restraining forces, or where there are no underlying potentially lethal conditions. In situations where there is doubt concerning the relative contributions of various aspects of the fatal episode e.g. drug toxicity, restraint, possible positional asphyxia, underlying significant medical conditions etc., it may be more useful to list the cause of death as "undetermined" and to then comment on the possible role, or not, of each potential predisposing factor.

While there appears to be no doubt that lethal and nonlethal episodes of excited delirium do occur, there is a lack of both a consistent definition and a clear understanding of the precise etiology and pathophysiological pathways $[2,8,18]$. The association of these episodes with aggressive and aberrant behavior and possible illicit drug taking will often result in the involvement of law enforcement officers [20]. Thus, dissecting out the story line and potential lethal mechanisms remains a vital component and an important challenge in each case. It is also important to avoid becoming bogged down in the mire of semantic discussions - no matter what terminology is used, it is apparent that some individuals will collapse and die in an agitated state during encounters with police for reasons that are often far from clear.

\section{References}

1. Hall CA. Excited delirium. In: Payne-James J, Byard RW, editors. Encyclopedia of forensic and legal medicine, vol. 2. 2nd ed. Oxford: Academic Press; 2016. p. 441-52.

2. Mash DC. Excited delirium and sudden death: a syndromal disorder at the extreme end of the neuropsychiatric continuum. Front Physiol. 2016;7:435.

3. Sullivan L. Death by excited delirium: diagnosis or coverup? http:// www.npr.org/templates/story/story.php?storyId=7608386. Accessed 1 July 2017.

4. Bell LV. On a form of disease resembling some advanced stages of mania and fever, but so contradistinguished from any ordinary observed or described combination of symptoms as to render it probable that it may be overlooked and hitherto unrecorded malady. Am J Insanity. 1849;6:97-127.

5. Vilke GM, DeBard ML, Chan TC, Ho JD, Dawes DM, Hall C, et al. Excited delirium syndrome (ExDS): defining based on a review of the literature. J Emerg Med. 2012;43:897-905.

6. Byard RW, Cox M, Stockham P. Blunt craniofacial trauma as a manifestation of excited delirium with new designer drugs. J Forensic Sci. 2016;61:1546-8.

7. Wetli CV, Fishbain DA. Cocaine-induced psychosis and sudden death in recreational cocaine users. J Forensic Sci. 1985;30:873-80. 
8. Lipsedge M. Excited delirium: a psychiatric review. Med Sci Law. 2016;56:121-7.

9. Gill JR. The syndrome of excited delirium. Forensic Sci Med Pathol. 2014;10:223-8.

10. Byard RW, Summersides G, Thompson A. Muscle pallor - a macroscopic marker of cocaine-induced rhabdomyolysis. Forensic Sci Med Pathol. 2011;7:364-6.

11. Takeuchi A, Ahern TL, Henderson SO. Excited delirium. West J Emerg Med. 2011;12:77-83.

12. Byard RW, Wick R, Simpson E, Gilbert JD. The pathological features and circumstances of death of lethal crush/traumatic asphyxia in adults - a 25-five year study. Forensic Sci Int. 2006;159:200-5.

13. Byard RW. Issues in the classification and pathological diagnosis of asphyxia. Aust J Forensic Sci. 2011;43:27-38.

14. Byard RW, Wick R, Gilbert JD. Conditions and circumstances predisposing to death from positional asphyxia in adults. J Forensic Legal Med. 2008;15:415-9.
15. Otahbachi M, Cevik C, Bagdure S, Nugent K. Excited delirium, restraints, and unexpected death: a review of pathogenesis. Am J Forensic Med Pathol. 2010;31:107-12.

16. Jauchem JR. Deaths in custody: are some due to electronic control devices (including Taser ${ }^{\circledR}$ devices) or excited delirium? J Forensic Legal Med. 2010;17:1-7.

17. Vilke GM, Bozeman WP, Dawes DM, DeMers G, Wilson MP. Excited delirium syndrome (ExDS): treatment options and considerations. J Forensic Legal Med. 2012;19:117-21.

18. Vilke GM, Payne-James J, Karch SB. Excited delirium syndrome (ExDS): redefining an old diagnosis. J Forensic Legal Med. 2012;19:7-11.

19. Coroner's Court of Victoria, Finding - Inquest into the death of Odisseas Vekiaris. http://www.coronerscourt.vic.gov.au/home/ coroners+written+findings/findings+-+inquest+into+the+death+ of+odisseas+vekiaris. Accessed 1 July 2017.

20. Baldwin S, Hall C, Bennell C, Blaskovits B, Lawrence C. Distinguishing features of excited delirium syndrome in non-fatal use of force encounters. J Forensic Legal Med. 2016;41:21-7. 